\title{
Neurological complications in patients with SARS-CoV-2 infection: a systematic review
}

\author{
Complicações neurológicas em pacientes infectados pelo SARS-CoV-2: uma revisão sistemática \\ Renato Puppi MUNHOZ1', José Luiz PEDROSO², Fábio Augusto NASCIMENTO³, Sergio Monteiro de ALMEIDA4, \\ Orlando Graziani Povoas BARSOTTINI², Francisco Eduardo C CARDOSO5. Hélio A Ghizoni TEIVE 6
}

\begin{abstract}
Background: As the COVID-19 pandemic unfolds worldwide, different forms of reports have described its neurologic manifestations. Objective: To review the literature on neurological complications of SARS-CoV-2 infection. Methods: Literature search performed following systematic reviews guidelines, using specific keywords based on the COVID-19 neurological complications described up to May $10^{\text {th }}, 2020$. Results: A total of 43 articles were selected, including data ranging from common, non-specific symptoms, such as hyposmia and myalgia, to more complex and life-threatening conditions, such as cerebrovascular diseases, encephalopathies, and Guillain-Barré syndrome. Conclusion: Recognition of neurological manifestations of SARS-CoV-2 should be emphasized despite the obvious challenges faced by clinicians caring for critical patients who are often sedated and presenting other concurrent systemic complications.
\end{abstract}

Keywords: Coronavirus Infections; COVID-19; Neurology; Guillain-Barré Syndrome; Encephalitis; Stroke.

RESUMO

Introdução: À medida que a pandemia da COVID-19 se desenvolve em todo o mundo, diferentes tipos de publicações descreveram suas manifestações neurológicas. Objetivo: Revisar a literatura sobre complicações neurológicas da infecção por SARS-CoV-2. Métodos: A pesquisa bibliográfica foi realizada seguindo diretrizes de revisões sistemáticas, usando palavras-chave específicas baseadas nas complicações neurológicas da COVID-19 descritas até 10 de maio de 2020. Resultados: Foram selecionados 43 artigos, incluindo descrições que variam de sintomas comuns e inespecíficos, como hiposmia e mialgia, a condições mais complexas e com risco de vida, como doenças cerebrovasculares, encefalopatias e síndrome de Guillain-Barré. Conclusão: O reconhecimento das manifestações neurológicas da SARS-CoV-2 deve ser enfatizado apesar dos óbvios desafios enfrentados pelos clínicos que cuidam de pacientes críticos, muitas vezes sedados e apresentando outras complicações sistêmicas concomitantes.

Palavras-chave: Infecções por Coronavírus; COVID-19; Neurologia; Síndrome de Guillain-Barré; Encefalopatias; Acidente Vascular Cerebral; Mialgia.

\section{INTRODUCTION}

Coronaviruses (CoV) belong to the Coronaviridae family, Nidovirales order. These viruses are enveloped, have a positivesense single-stranded RNA genome and are classified into four genera: alpha, beta, gamma, and delta. The alpha, beta, and delta $\mathrm{CoV}$ infect mammals. However, they all have the ability to jump between species, leading to the emergence of severe respiratory syndromes in humans, such as the Middle East respiratory syndrome (MERS) caused by MERS-CoV, the severe acute respiratory syndrome (SARS) caused by SARS-CoV, and, more recently, COVID-19, caused by SARS-CoV- $2 .{ }^{1}$

CoV-related disease was first described in 1931, with the isolation of the first human virus per se (HCoV-229E) in 1965.

\footnotetext{
${ }^{1}$ University of Toronto, Toronto Western Hospital, Movement Disorders Centre, Toronto ON, Canada.

${ }^{2}$ Universidade Federal de São Paulo, Escola Paulista de Medicina, Department of Neurology and Neurosurgery, São Paulo SP, Brazil.

${ }^{3}$ Baylor College of Medicine, Department of Neurology, Houston TX, USA.

«Universidade Federal do Paraná, Hospital de Clínicas, Neuroinfection Outclinic, Virology Laboratory, Medical Pathology Department, Curitiba PR, Brazil.

${ }^{5}$ Universidade Federal de Minas Gerais, Hospital das Clínicas, Movement Disorders Unit, Neurology Service, Internal Medicine Department, Belo Horizonte MG, Brazil.

${ }^{6}$ Universidade Federal do Paraná, Hospital de Clínicas, Internal Medicine Department, Neurology Service, Curitiba PR, Brazil.

Renato Puppi MUNHOZ (iD) https://orcid.org/0000-0002-4783-4067; José Luiz PEDROSO (iD https://orcid.org/0000-0002-1672-8894;

Fábio Augusto NASCIMENTO (D) https://orcid.org/0000-0002-7161-6385; Sergio Monteiro de ALMEIDA (iD) https://orcid.org/0000-0001-5690-105X;

Orlando Graziani Povoas BARSOTTINI (D) https://orcid.org/0000-0002-0107-0831; Francisco Eduardo C CARD0SO ID https://orcid.org/0000-0003-0808-0116; Hélio A Ghizoni TEIVE (iD) https://orcid.org/0000-0003-2305-1073

Correspondence: Renato Puppi Munhoz; E-mail:renato.munhoz@uhn.ca

Conflict of interest: There is no conflict of interest to declare.
}

Received on April 15, 2020; Received in its final form on April 27, 2020; Accepted on May 1, 2020. 
Until the epidemic of SARS in late 2002, only two human CoV types were known - HCoV-229E and HCoV-OC43. Since then, another six human CoV have been identified, implicated as causes of cold (2 to 10\%), the second most common after rhinoviruses, manifesting in adults with limited symptoms, including rhinitis, sore throat, and dry cough. Although $\mathrm{CoV}$ also cause enteric and systemic diseases, most infections are mild, resolving spontaneously. ${ }^{1}$

Despite the fact that the neurotropic, neuro-invasive and neurovirulent capabilities of SARS-CoV and MERS-CoV have been described in animals and humans leading to encephalitis, meningitis or encephalomyelitis, the specific mechanisms of this process are not well characterized. ${ }^{2}$

SARS-CoV-2 was first described in Wuhan, China, in December 2019. In a few months, it has spread to nearly every country throughout the world, with large economic, social and health impacts, in addition to an overwhelming number of deaths. ${ }^{3}$ The clinical syndrome caused by SARS-CoV-2 is called COVID-19. In a fair proportion of cases, COVID19 symptoms are clinically indistinguishable from those of common flu, namely fever (90\%), cough (70\%), myalgia and fatigue $(50 \%)$, less frequently headache $(8 \%)$, and diarrhea $(5 \%)$, while anosmia and ageusia may be initial manifestations. ${ }^{3}$ A smaller proportion of severe cases present more intense lower respiratory tract disease, often requiring respiratory assistance. On the opposite side of the spectrum, $5 \%$ of cases are asymptomatic. ${ }^{4}$ Moreover, as the pandemic unfolds, there is growing evidence that COVID-19 is a multisystemic disease. For instance, renal failure is more common than initially realized, whereas cardiac dysfunction has also been well described in many SARS-CoV-2 infected individuals. ${ }^{5,6}$

Although the data are preliminary, a substantial proportion of patients develop neurological complications associated to COVID-19. Data from a series of patients from Wuhan, China, indicate that neurological abnormalities are found in $36.4 \%$ of hospitalized patients. ${ }^{7}$ It is likely that this figure may vary depending on several factors, such as clinical setting (outpatients versus inpatients), demographic features (age, sex, ethnicity) and methodology of neurological assessment.

The mechanism of neurological involvement in COVID-19 remains to be determined, but it is probably heterogeneous and multifactorial, including direct involvement of the brain due to SARS-CoV-2, auto-immune factors, inflammation ("cytokine storm"), drug side-effects, metabolic disturbances and critical care neuropathy. ${ }^{89}$ The data from Wuhan show that most complications have an early onset suggesting that direct involvement of the nervous system by the virus is an important factor. This is unlikely what happened with SARS, whose neurological findings had a late onset, suggesting an underlying autoimmune mechanism. ${ }^{8}$

Absence of reports of phenomena such as chorea, myoclonus, opsoclonus and ataxia, and the scarcity of cases of acute demyelinating polyradiculopathy suggest that immune mediated phenomena are not as common in COVID-19 although caution is warranted in interpreting such data, because many of these autoimmune manifestations have a prolonged latency. Moreover, there are descriptions of ataxia, stroke associated with antiphospholipid antibodies and even Guillain-Barré syndrome (GBS) in individuals with COVID-19, ${ }^{7,10,11}$ Another important question about the interplay between infection with SARS-CoV-2 and the nervous system is if pre-existing neurological diseases increase the risk of severe complications, such as respiratory failure in COVID-19. As of the writing of this review, there is no evidence that this is the case. ${ }^{9}$ Yet, intuitively, one may argue that conditions associated to respiratory issues (e.g., severe myopathies, neuropathies, neuromuscular junction disorders), as well as degenerative diseases, such as advanced Parkinson's disease (PD), render subjects prone to a more malignant course of COVID-19. Despite the lack of data, one also expects worsening of neurological conditions as a result of COVID-19. Unpublished experience of the authors confirms this may happen in PD, which is not surprising, considering that it is well known that patients with underlying degenerative disease, including dementing conditions, develop significant, often irreversible, worsening as a result of clinical disturbances. Other potential issues that may negatively interfere with the course of neurological illnesses are social isolation and lack of exercise due to staying at home and social distancing. ${ }^{12}$

Finally, at a global level, the worsening of the pandemic has rightly led the health systems to focus on preventing and combating COVID-19. There is growing evidence that patients with other medical conditions are facing difficulties in accessing health providers despite a substantial increase in telemedicine. In the New York City area, for instance, there has been an $800 \%$ increase in cardiac arrest deaths at home after the onset of the COVID-19 pandemic. ${ }^{13}$ As such, it is possible that people with neurological diseases are also having trouble in contacting their neurologists and the neurological community must strive to keep offering care to their patients despite the hardships created by the COVID-19 pandemic.

The aim of this article is to provide a review of the existing data, including epidemiology, pathophysiology, and clinical and laboratory findings of neurological findings in COVID-19.

\section{METHODS}

A literature search was performed following the Preferred Reporting Items for Systematic Reviews and Meta-Analyses guidelines ${ }^{14}$ in both MEDLINE and LILACS databases, using "coronavirus COVID-19", "COVID-19", "COVID 19", "SARS-CoV-2" as search terms, along with "neurology", "neurological" and the specific disorder designations: cerebrovascular, stroke, encephalopathy, encephalitis, 
meningitis, myelitis, Guillain Barré, Guillain-Barré syndrome, myalgia, headache, hyposmia, anosmia, ageusia, in the medical subject headings, title, abstract, or author-supplied keywords. Research was broadened to include screening of reference lists of systematic review articles for additional studies initially missed or presented only in abstract form. No restrictions were predetermined as to the year of the study, with investigations dating from the earliest available date until May $10^{\text {th }}$, 2020. Only studies in English were included. We analyzed publications with laboratory confirmed cases only, ranging from relatively large series to more limited case series and case reports (Figure 1).

Figure 1 shows the flow diagram for inclusion of articles.

\section{RESULTS}

Table 1 presents a summary of the main findings of the review, which are described in more details below.

\section{Cerebrovascular disease}

Patients with SARS-CoV-2 infection, especially critically ill elderly cases, appear to be more susceptible to develop cerebrovascular disease (CVD), including cerebral hemorrhage and ischaemic stroke. The cases described so far indicate that ischaemic CVD in this setting may have distinct characteristics, with implications for diagnosis and treatment: the vast majority had large-vessel occlusion, and a significant
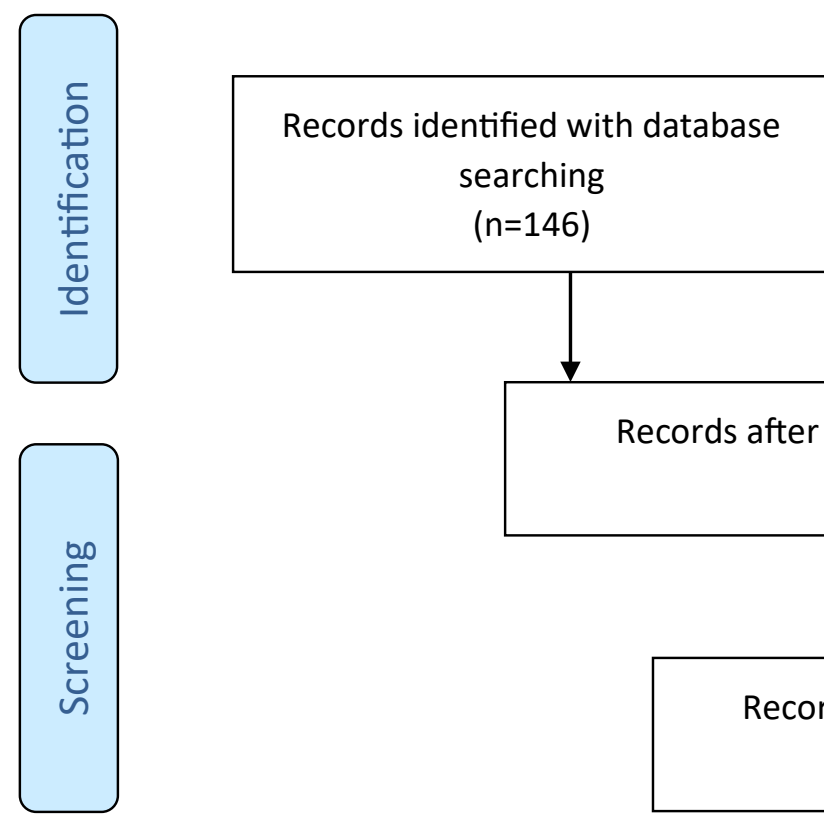

Records after removing duplicates

Additional records identified with other sources $(n=3)$
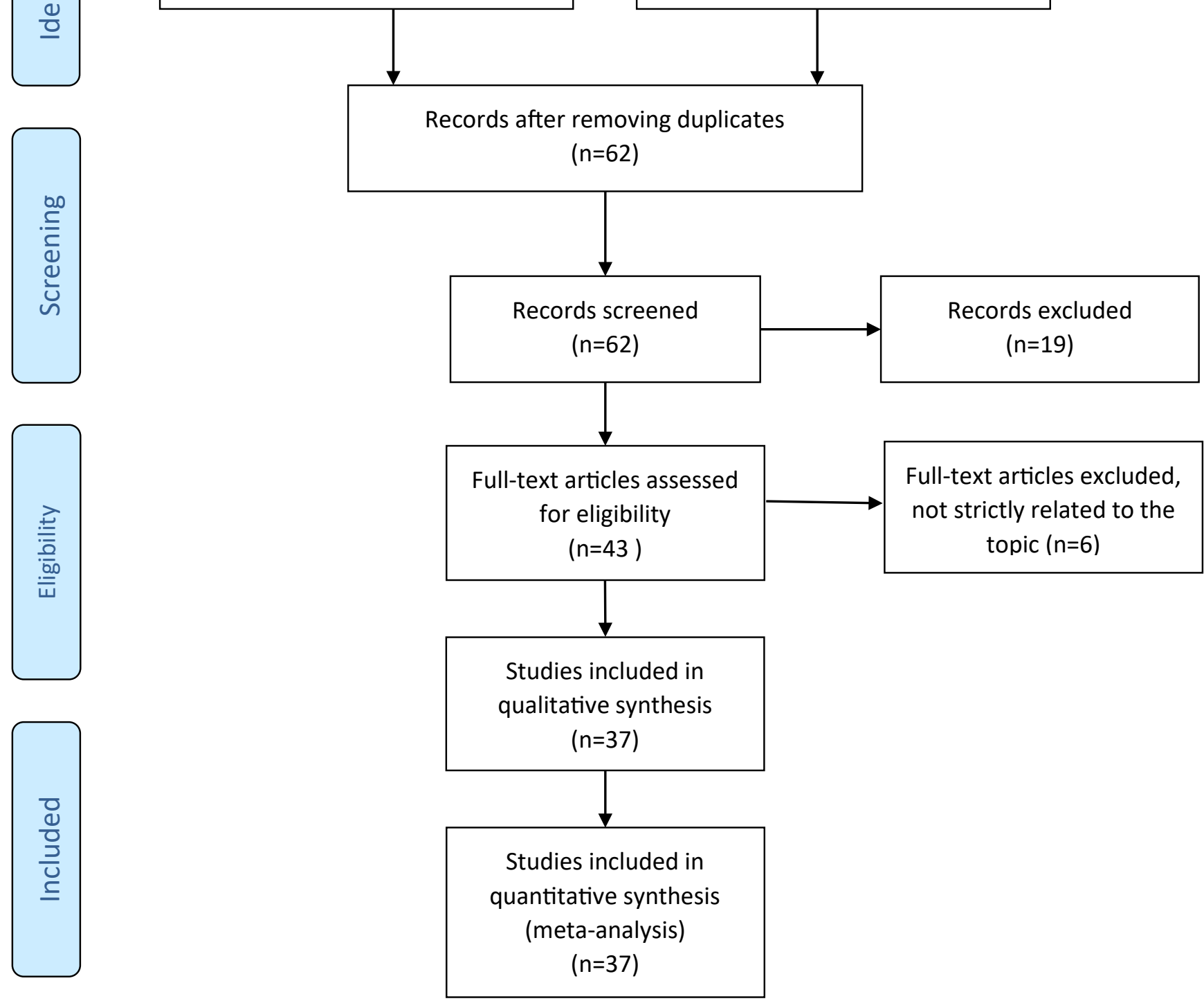
$n=19)$

Figure 1. Inclusion of articles by Preferred Reporting Items for Systematic Reviews and Meta-Analyses 2009 flow diagram. 
number had multiple territories affected. Although some of the reported events were the first-ever in these patients medical history, most cases already had other cerebrovascular risk factors, such as hypertension, diabetes mellitus, hyperlipidemia, smoking or previous stroke history. ${ }^{15,16}$ On the other hand, two recent reports identified a total of six cases of large-vessel stroke in SARS-CoV-2 patients younger than 50 (33-49) years of age. Three had no vascular risk factors, five had anterior circulation strokes, and all had mild to moderate symptoms of the viral infection. Most remained severely disabled at last follow-up assessment. ${ }^{17,18}$

There is strong evidence that vascular complications may arise for the most part due to the well recognized potentially fatal inflammatory storm, which reflects a hyperactivation of inflammatory factors and dysfunction of the coagulation system, especially D-dimer and platelet abnormalities, increasing the risk of CVD. Furthermore, hypertense SARS-CoV-2 infected patients frequently develop changes in blood pressure, potentially explained by the fact that the virus specifically binds to angiotensin converting enzyme 2 (ACE2) receptors. In addition, thrombocytopaenia, a risk factor for cerebral haemorrhage, is distinctively found in severe cases of the disease ${ }^{15}$ This equation may be further complicated by cardiogenic and hematologic factors, as data from previous coronavirus and influenza epidemics suggest that viral infections can trigger acute arrhythmias, exacerbation of heart failure, and myocarditis. ${ }^{3,19}$ In turn, Zhang et al. ${ }^{10}$ described severe coagulopathy, multiple infarcts (brain, upper and lower extremities), severe coagulopathy and the presence of antibodies against cardiolipin and $\beta_{2}$-glycoprotein $\mathrm{I}$ in patients with SARS-CoV-2 infection.
The aforementioned evidence is partially corroborated by clinical data derived from a case series of SARS-CoV-2 infected patients. Mao et al. ${ }^{7}$ identified neurologic symptoms in $45.5 \%$ of patients in a series of 88 severely infected patients, $5.7 \%$ of them presenting either ischemic or hemorrhagic CVD. AsadiPooya and Simani ${ }^{20}$ published a systematic review of studies on the neurological findings of SARS-CoV-2 infected patients, identifying ischemic CVD in about $5 \%$, in addition to cases of cerebral venous sinus thrombosis and cerebral hemorrhage. CVD cases were significantly older, more likely to present with severe infection, to have cardiovascular risk factors, and to show increased serum markers of inflammatory response and hypercoagulable state. Overall, more than a third of these CVD patients eventually died. Although a pooled analysis of studies on this topic showed that stroke was associated to a 2.5-fold increase in odds of severe COVID-19, there was no statistically significant association of stroke with mortality. ${ }^{21}$ Figure 2 illustrates a case of SARS-CoV-2 infection associated to cerebral hemorrhage seen by one of the authors of this review.

Finally, Khosravani et al. ${ }^{22}$ developed guidelines entitled "Protected Code Stroke" for the management of hyperacute stroke during the coronavirus disease pandemic, providing considerations for screening, personal protective equipment and crisis resource management.

\section{Encephalopathy}

The largest data available on neurologic complications associated to SARS-CoV-2 arose from a retrospective case series of 214 hospitalized patients with confirmed COVID-19.7 Out of the 214 patients (36.4\%), 78 were found

Table 1. Most common neurological manifestations of SARS-CoV-2 infection.

\begin{tabular}{|c|c|c|c|c|}
\hline $\begin{array}{l}\text { Neurological } \\
\text { manifestation }\end{array}$ & Frequency & Presentation & Risk factors / Associated features & References \\
\hline $\begin{array}{l}\text { Cerebrovascular } \\
\text { disease }\end{array}$ & $2.8-5.7 \%$ & $\begin{array}{l}\text { Mostly ischemic; rare hemorrhage } \\
\text { and venous thrombosis }\end{array}$ & $\begin{array}{l}\text { Critically ill (?), pre-existing } \\
\text { vascular risk factors }\end{array}$ & $7,10,15,16,17,18,19,20,21$ \\
\hline Encephalopathy & $\begin{array}{c}9 \% \\
\text { (hypoxic) }\end{array}$ & $\begin{array}{c}\text { Hypoxic encephalopathy; } \\
\text { case reports of necrotizing } \\
\text { hemorrhagic encephalopathy and } \\
\text { encephalitis }\end{array}$ & Critically ill, predictor of death & $7,23,24,2,26,27,28,29,30,31$ \\
\hline $\begin{array}{l}\text { Guillain-Barré } \\
\text { Syndrome }\end{array}$ & Rare & $\begin{array}{c}\text { Six out of } 11 \text { cases reported } \\
\text { presented variant forms, including } \\
\text { AMAN and MFS }\end{array}$ & Only described in adults so far & $11,38,39,40,41,42$ \\
\hline Anosmia/ageusia & $5.1-88 \%$ & $\begin{array}{l}\text { Both symptoms may occur in } \\
\text { association; early feature with } \\
\text { delayed resolution }\end{array}$ & $\begin{array}{l}\text { Younger age, female; no correlation } \\
\text { with disease severity }\end{array}$ & $7,45,46,47,48$ \\
\hline Myalgia & $10.7-54 \%$ & $\begin{array}{l}\text { Associated with fatigue, abnormal } \\
\text { CK, and inflammatory markers }\end{array}$ & $\begin{array}{l}\text { Critically ill adults with multiple } \\
\text { organ damage }\end{array}$ & $7,58,59,60,61,62$ \\
\hline Headache & $8-34 \%$ & Non-specific & $\begin{array}{l}\text { Mostly benign; also described as } \\
\text { part of severe processes }\end{array}$ & $3,7,8,33$ \\
\hline $\begin{array}{l}\text { Other } \\
\text { manifestations }\end{array}$ & N/A & Ataxia, seizures, dizziness & $\begin{array}{l}\text { Described as part of severe } \\
\text { processes (encephalopathy, stroke) }\end{array}$ & $7,24,25,26$ \\
\hline
\end{tabular}

N/A: not applicable; AMAN: acute motor axonal neuropathy; MFS: Miller-Fisher Syndrome. 
to have nervous system-associated manifestations, which were divided into three subgroups: central nervous system (CNS), peripheral nervous system (PNS), and skeletalrelated injury. CNS involvement, in particular, was seen in 53 patients (24.8\%); these manifestations comprised dizziness $(n=36 ; 16.8 \%)$, headache $(n=28 ; 13.1 \%)$, impaired consciousness $(\mathrm{n}=16 ; 7.5 \%)$, acute CVD $(\mathrm{n}=6 ; 2.8 \%)$, ataxia $(\mathrm{n}=1$; $0.5 \%)$, and seizure ( $\mathrm{n}=1 ; 0.5 \%)$. Among these CNS-related manifestations, impaired consciousness and CVD were significantly more common in patients with severe versus nonsevere COVID-19 infection. The authors defined impaired consciousness as any change in level (e.g., somnolence, stupor, and coma) and/or content of consciousness (e.g., confusional state and delirium). In other words, an encephalopathic state. As to seizures, there was one patient in the study who experienced acute limb twitching, foaming in the mouth and loss of consciousness for three minutes. Magnetic resonance imaging (MRI) and invasive procedures, such as lumbar puncture, were avoided given the risk of cross-contamination. Therefore, it is not possible to further characterize these patients' encephalopathy with confidence. ${ }^{7}$

A similar retrospective study, also from China, included 274 patients with COVID-19: 113 deceased and 161 recovered patients. ${ }^{23}$ Headache or dizziness were the initial presenting symptoms in 31 patients (11\%) and 21 patients (8\%), respectively. Hypoxic encephalopathy was identified in 24 patients (9\%). Whereas headache and dizziness were similarly seen in the deceased and alive patient groups, hypoxic encephalopathy was more frequent in deceased patients $(n=23 / 113)$ in comparison to those from the recovered patient group $(n=1 / 161)$. The reported rate of confusional state was also 9\% in a similar Chinese retrospective series involving 99 patients with confirmed COVID-19 and pneumonia. ${ }^{24}$ In another Chinese retrospective multicenter study with 304 patients who had been either discharged or died, eight were encephalopathic (2.6\%; $n=8 / 304)$ : one obtunded, one delirious, and the remaining six comatose. Non-convulsive status epilepticus was excluded as a cause for altered mental status. ${ }^{25}$

A French case series reported on neurologic complications in a cohort of 58 patients with acute respiratory distress syndrome due to confirmed SARS-CoV-2 infection. ${ }^{26}$ Confusional state and agitation were seen in roughly two-thirds of patients. A total of 13 patients underwent brain MRI because of unexplained encephalopathy, eight of them showing leptomeningeal enhancement. Eight patients underwent electroencephalography (EEG), which only revealed nonspecific changes. Lastly, cerebrospinal fluid (CSF) analyses of seven patients were negative for SARS-CoV-2. The authors speculated on the underlying mechanism of neurologic injury in these patients, raising the possibility of multifactorial factors, including intensive care unit (ICU) related encephalopathy, cytokine storm, and the effect or withdrawal of medications.

Thefirstcase of presumedCOVID-19-associatedacutenecrotizing hemorrhagic encephalopathy ${ }^{27}$ was of a middle-aged
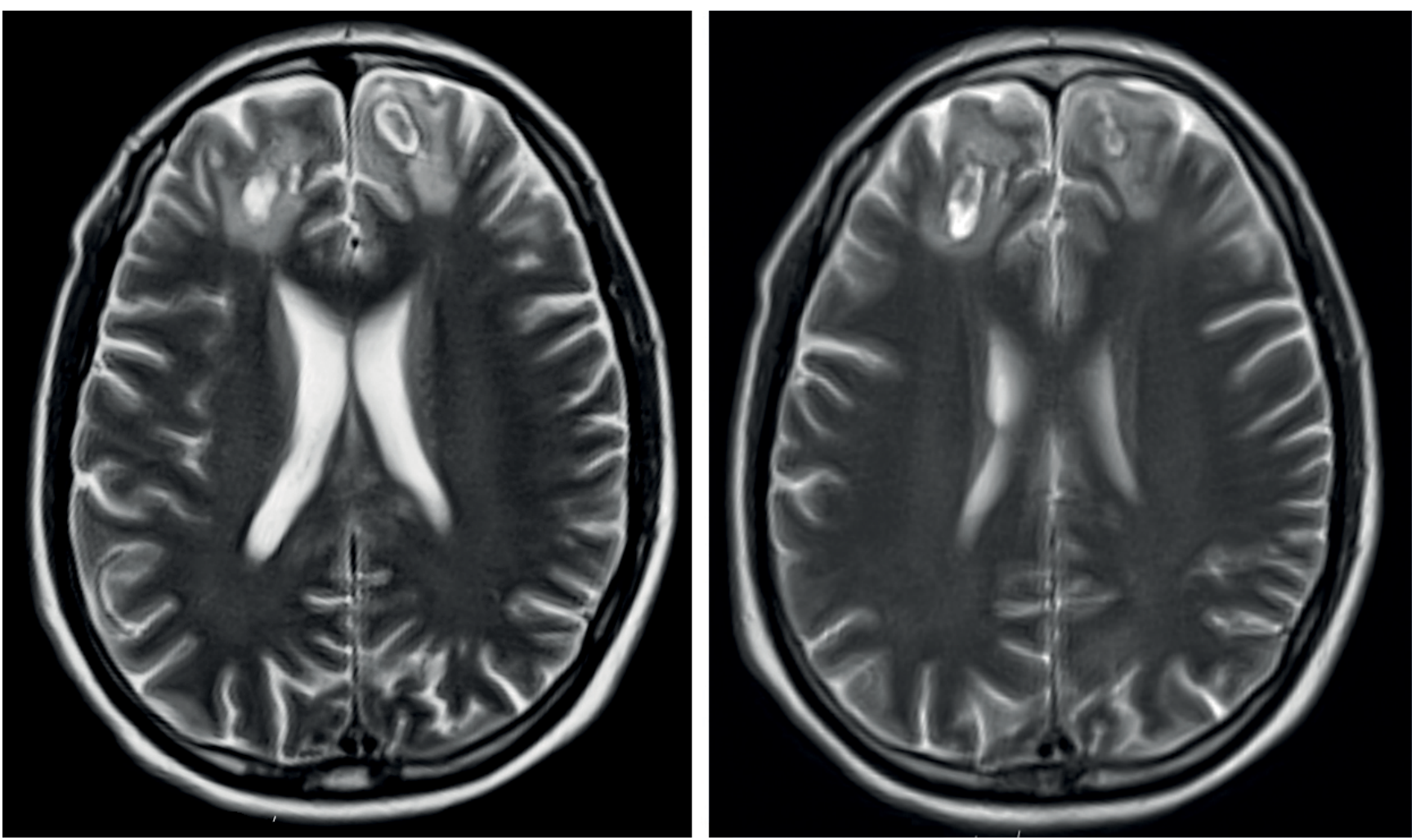

Figure 2. Brain MRI of a 53 year-old, critically ill male admitted to intensive care unit due to severe SARS-CoV-2 pneumonia. Axial T-2 imaging shows bifrontal lesions which, added by additional sequences, suggested subacute parenchymal hematomas. Further imaging showed diffuse petechial hemorrhage throughout most of the hemispheric grey matter, suggestive of coagulopathy. 
woman who presented respiratory symptoms along with fever and altered mentation. COVID-19 was confirmed with a nasopharyngeal swab. CSF studies were limited due to a traumatic lumbar puncture. The available tests reported by the authors included HSV-1, HSV-2, VZV and West Nile virus, which were all negative. SARS-CoV-2 was not tested in the CSF. Neuroimaging was remarkable for hemorrhagic, rimenhancing lesions in the bilateral thalamus, medial temporal lobes and subinsular regions. Computed tomography (CT) angiography and venography were normal. This patient was treated with intravenous immunoglobulin (IVIG), but details of outcome are unavailable. It is important to note the presumptive nature of this diagnosis because SARS-CoV-2 was not tested in this patient's CSF. Moreover, despite being rare, acute necrotizing encephalopathy may be caused by a myriad of pathogens, including influenza A and B, parainfluenza, varicella, and HHV6 ${ }^{28}$ In addition, two other reports should me mentioned. The first is a 54 year-old woman found unconscious at home and diagnosed with interstitial pneumonia due to SARS-CoV-2. Upon steady clinical deterioration, EEG showed focal frontotemporal seizure activity while brain and spine MRI revealed alterations of the periventricular white matter, bulbo-medullary junction and in both the cervical and thoracic spinal cord, hyperintense in T2WI, without restriction of diffusion or contrast enhancement. CSF examination was normal, including mutiple sclerosis markers and RT-PCR for SARS-CoV-2 and other viruses. The authors label the clinical presentation as brain and spine demyelinating lesions induced by a delayed immune response secondary viremia..$^{29}$ The second is a case of possible acute disseminated encephalomyelitis (ADEM) described in a female patient in her early forties with acute dysphagia, headache, dysarthria and encephalopathy, nine days after presenting with fever and respiratory symptoms. ${ }^{30}$ Chest imaging showed signs of pneumonia, whereas brain MRI T2 FLAIR imaging showed extensive patchy areas of abnormal signal involving bilateral frontoparietal white matter, anterior temporal lobes, basal ganglia, external capsules and thalami suggestive of a demyelinating process. Vascular imaging was normal. CSF analysis was also normal, including PCR for meningitis and encephalitis causing agents. The testing for SARS-CoV-2 infection was positive. The patient was treated with hydroxychloroquine, ceftriaxone and a five-day course of IVIG with overall good response. A major caveat in this case is the fact that it was published in a non peer-reviewed source; thus, the occurrence of ADEM in this context still lacks confirmation. ${ }^{30}$

It was not until a few days later that the first confirmed case of CNS infection by SARS-CoV-2 was published, ${ }^{31}$ confirming the neuroinvasive properties of the virus. The patient was a 24 year-old man who developed headache, fatigue and fever roughly a week before presenting to the hospital due to a convulsive episode. Meningeal irritation was identified with examination warranting workup with a head $\mathrm{CT}$ and lumbar puncture. The former did not show cerebral edema, whereas the latter revealed increased opening pressure $\left(320 \mathrm{~mm} \mathrm{H}_{2} \mathrm{O}\right)$, mononuclear-predominant pleocytosis $(12 / \mathrm{uL})$, no red blood cells, and presence of SARS-CoV-2 RNA. Serum HSV-1 and VZV IgM antibodies were negative. Neuroimaging showed right mesial temporal encephalitis and right ventriculitis without abnormal enhancement; it also showed pan-paranasal sinusitis. Chest imaging confirmed pneumonia, although nasopharyngeal swab was negative for SARS-CoV-2. This patient was treated with acyclovir, ceftriaxone, vancomycin and steroids, as well as anti-convulsants. ${ }^{31}$

Later, three additional patients with SARS-CoV-2 infection were reported as having meningoencephalitis presumably related to the virus. The first, a Chinese man, had the diagnosis of CNS infection based on clinical grounds altered mentation and meningeal signs. This patient's CSF studies were within normal limits, including negative testing for SARS-CoV-2, and head CT with no acute findings. Mental confusion resolved by the time of discharge. ${ }^{32}$ The second patient was a middle-aged woman who presented to an emergency department in the United States with fever, headache, and new-onset seizure. Initial examination was notable for meningeal signs. Head CT was normal, but CSF studies showed lymphocytic pleocytosis and increased protein and red blood cells; SARS-CoV-2 was not tested and HSV PCR was negative. Although the patient did not have significant respiratory symptomatology, she tested positive for SARS-CoV-2. Her hospital course was complicated by encephalopathy despite no recurrence of seizures after anticonvulsant medication was initiated; EEG showed generalized slowing only. There is no available information on follow-up. ${ }^{33}$ The third case is of a 40 year-old man presenting acute brainstem dysfunction three days after onset of symptoms that eventually led to the diagnosis of SARS-CoV-2 infection. Brain and spine MRI showed changes in keeping with inflammation of the brainstem and the upper cervical cord, leading to a diagnosis of rhombencephalitis. ${ }^{34}$ Altered mental status, hyperreflexia and meningeal signs were also observed in a 64 year-old man from China, whose main symptoms were fever and respiratory-related symptoms; his testing was remarkable for negative SARS-CoV-2 in the CSF, but positive in a throat swab. ${ }^{35}$

CNS involvement in the context of COVID-19 may be truly neurologic, a consequence of systemic injury, or a combination of both. The neurotropic nature of SARS-CoV-2 is supported by the observation of viral spread into $\mathrm{CSF}^{35}$ and the possible neuroinvasive potential of this virus. The latter is based on the similarity between SARS-CoV-2 and SARS-CoV, which in turn has established neuronal invasion capabilities. ${ }^{36,37}$ Other possible mechanisms of CNS insult secondary to COVID-19 include hypoxic injury from lung disease, overactive systemic immune response and resultant cytokine storm (including IL-6, IL-12, IL-15, and TNF-alpha), and damage to endothelium and blood-brain-barrier resulting in vascular injury. ${ }^{38}$ 


\section{Guillain-Barré syndrome}

GBS can potentially be linked to any viral infection and is a documented complication found in previous viral pandemics, including those due to Zika, chikungunya, dengue, and H1N1 influenza viruses. ${ }^{39}$ Due to the rising pandemics of SARS-CoV-2 infection since the early months of 2020, vigilance for signs and symptoms of GBS should be part of the assessment of patients with SARS-CoV-2 infection given that, although a rare event in general, GBS is a potentially treatable complication that may rise the viral infection lethality if not promptly identified.

As of the time of the writing of this review, 11 cases of GBS potentially linked to SARS-CoV-2 have been reported. ${ }^{11}$ The first affected patient, published in early-April 2020, was a 61 year-old woman who returned to Shanghai from Wuhan in mid-January 2020, four days before presenting to medical attention. At admission, she denied the typical signs of SARS-CoV-2 infection, had normal lung auscultation and, as such, was not tested for it. Her complaints were of a one-day history of progressive fatigue and areflexic symmetric weakness in the lower extremities. Initial blood workup showed low lymphocyte count and thrombocytopenia. Three days after admission, symptoms were more profound, also affecting her upper extremities and added by a decreased sensation to light touch and pinprick. At this point, CSF indicated normal cell count, but increased protein levels of $124 \mathrm{mg} / \mathrm{dL}$ (8-43 mg/dL). Nerve conduction studies performed on the fifth day after admission were in keeping with a diffuse demyelinating process. A diagnosis of GBS was established and a course of IVIG was started. Eight days after admission (11 days since returning from Wuhan), she developed dry cough and fever $\left(38.2^{\circ} \mathrm{C}\right)$, and a chest $\mathrm{CT}$ showed ground-glass opacities in both lungs. At this point, oropharyngeal swabs tested positive for SARS-CoV-2 on RT-PCR assay. The patient was isolated, received supportive care and empirical antivirals (arbidol, lopinavir, and ritonavir). She improved gradually and was discharged 30 days after admission with normal global strength and reflexes, no respiratory symptoms, and a negative SARS-CoV-2 test. ${ }^{11}$ Although the patient was not tested for the viral infection upon admission, the co-ocurrence of SARS-CoV-2 infection and GBS intuitively raises the possibility of a causal relation. The pattern, however, is, if anything, that of a parainfectious process (based on the recent travel history and bloodwork findings on admission), rather than the classic post-infectious pattern reported during previous pandemics, Zika virus being the best example. Besides that, one can speculate that IVIG treatment may have triggered the presentation of symptoms and signs of the viral infection.

The second case, published in mid-April, was of a 65 year-old male patient from Iran, presenting typical symptoms of acute progressive symmetric ascending quadriparesis, two weeks after been diagnosed with SARS-CoV-2 pneumonia based on positive RT-PCR and chest CT imaging, and treated with hydroxychloroquine, lopinavir/ritonavir and azithromycin. Neurophysiological study was consistent with acute axonal polyradiculopathy variant of GBS. CSF analysis was not performed due to a lack of consent, and the patient was treated with IVIG ( $0.4 \mathrm{~g} / \mathrm{kg} /$ day for five days). No details regarding the outcome were provided. ${ }^{40}$ At the same time, another case of a 54-year-old male with a two-day history of numbness and progressive weakness of his lower extremities was reported. Upon initial assessment, the patient also had fever and cough over the past 10 days, and diarrhea. Neurological examination confirmed an areflexic motor strength deficit. SARS-CoV-2 infection was confirmed with RT-PCR with chest imaging showing bilateral basilar lung opacities. Based on clinical presentation, the diagnosis of GBS was presumed even though the authors did not pursue further paraclinical confirmation and started IVIG $(0.4 \mathrm{~g} / \mathrm{kg} /$ day for five days) and hydroxychloroquine. The outcome was positive, with improvement in respiratory and neurological status. ${ }^{41}$

The most solid report on this topic came from Italy, including five patients diagnosed with GBS after RT-PCR confirmed SARS-CoV-2 infection. Presentation were lower-limb weakness and paresthesia in four patients and facial diplegia followed by ataxia and paresthesia in one patient, with tetraplegia evolving over a period of 36 hours to four days in four patients. The interval between the onset of SARS-CoV-2 infection and GBS symptoms ranged from five to 10 days. CSF analysis showed normal white cell count in all of them, and elevated protein in three. Electrophysiological studies were consistent with an axonal variant of GBS in three patients, and a demyelinating process in two. All patients were treated with IVIG, one had a repeated IVIG course and another one was treated with plasma exchange. Outcomes varied: four weeks after treatment, two remained in the ICU receiving mechanical ventilation, two were still recovering with significant weakness, and one had been discharged, able to walk independently. ${ }^{42}$

Another Italian report arguably had a parainfectious presentation and was, unfortunately, the first fatal case of GBS in this setting: a 71 year-old man with rapidly progressive ascending tetraparesis, paresthesias, and areflexia. CSF and nerve conduction studies confirmed a severe form of acute polyradiculoneuritis with prominent demyelinating features. Given that the patient also presented with a one-week complaint of fever and dyspnea, he was tested for SARS-CoV-2 infection and underwent a chest $\mathrm{CT}$, testing positive for COVID-19 pneumonia. Despite prompt treatment with IVIG, antiviral therapy (lopinavir and ritonavir), and hydroxychloroquine in intensive care setting, the patient died a few hours after admission. ${ }^{43}$

Finally, a Spanish report of two cases, one presenting with anosmia, ageusia, oculomotor palsy, ataxia, areflexia, albuminocytologic dissociation and positive testing for GD1b-IgG antibodies, five days after developing cough, malaise, headache, low back pain and fever with positive RT-PCR for SARS-CoV-2; and another of a 39 year-old man 
with ageusia, bilateral abducens palsy, areflexia and albuminocytologic dissociation, three days after developing diarrhea and fever with positive testing for SARS-CoV-2 virus infection. The first patient was treated with IVIG and both made a complete neurological recovery, except for residual anosmia and ageusia. ${ }^{44}$

Until the writing of the present review, there seems to be reasonably good evidence for an association of SARS-CoV-2 infection, GBS and GBS variants. Furthermore, the apparent dysproportional frequency of axonal damage raises the possibility of the occurrence of more severe forms in this setting. Awareness for this specific complication is advised, as well its inclusion in the differential diagnosis of cases with suspected critical-illness polyneuropathy. Conversely, it also seems reasonable to test new GBS cases for the virus during the ongoing pandemic.

\section{Olfactory and taste disorders}

Anosmia or hyposmia refer, respectively, to the absence or reduction of the sense of smell, whereas ageusia is the loss of taste. Both conditions, anosmia or ageusia, may occur in isolation (idiopathic) or associated with structural damage to the nervous system. Several neurological diseases may present with olfactory impairment, such as head trauma, multiple sclerosis, PD and Alzheimer's disease. ${ }^{45}$ More frequently, 11 to $40 \%$ of patients with upper airway tract infection, common cold or influenza may present anosmia or hyposmia. ${ }^{46}$

Recently, a few studies have identified both anosmia and ageusia as frequent and marked clinical features observed in SARS-CoV-2 infection. Giacomelli et al. ${ }^{47}$ evaluated, with a simple questionnaire, 88 hospitalized patients with SARS-CoV-2 infection, detecting olfactory or taste disorders in $33.9 \%$ of patients, whereas both were subjectively detected at the same time in almost $20 \%$ of them. In terms of timing for the detection of these symptoms, $20.3 \%$ presented anosmia before admission, and for ageusia, 91\% described it before hospitalization. This study also observed that olfactory and/or taste disorders were more frequent in female and young patients.

In a larger multicentric study evolving 12 centers, Lechien et al.$^{48}$ evaluated 417 patients with SARS-CoV- 2 infection, and observed that $85.6 \%$ and $88.0 \%$ of patients reported olfactory and gustatory dysfunctions, respectively, and recovery rate was $44 \%$ in a short period. It is noteworthy that $11.8 \%$ of the patients had olfactory dysfunction as the presenting symptom. This study also showed that females were significantly more affected.

Beltrán-Corbellini et al. ${ }^{49}$ evaluated the frequency of taste and smell disorders in patients with SARS-CoV-2 infection and compared them to patients with influenza infection as a control group, showing that these deficits were significantly more frequent in SARS-CoV-2 infection than in the controls. Moreover, another study demonstrated that patients with
SARS-CoV-2 infection may present isolated anosmia, without other upper airway infection symptoms or signs. ${ }^{50}$

Although pathophysiological mechanisms related to anosmia and ageusia in SARS-CoV-2 are not completely understood, a mouse model has demonstrated penetration of the virus through the olfactory bulb. ${ }^{51}$ Furthermore, the cells of the oral mucosa are comprised by ACE2 receptor, which is used by the virus to infiltrate into the cells. ${ }^{52}$ A dopaminergic pathway dysfunction is also presumed to be related to anosmia in patients infected by SARS-CoV- $2 .{ }^{53}$ Finally, SARS-CoV-2 may infect the inner lining of the nasal cavity, triggering localized inflammation. ${ }^{51}$

Overall, anosmia and ageusia are very common in SARSCoV-2, more frequently than observed in other upper airway infections, and must be included as a clinical clue to guide the investigation through serology or PCR testing. There is no specific treatment for anosmia and ageusia related to SARS-CoV-2 infection, recovery is variable and should occur in most of the affected patients after two or three weeks. A follow-up reassessment will be necessary to determine if these symptoms are indeed transient findings or permanent sequelae of SARS-CoV-2 infection.

\section{Myalgia}

Myalgia is a common symptom in the neurological clinical practice, which, in isolation, often represents a non-specific manifestation of several conditions ${ }^{54}{ }^{5 n}$ addition, myalgia has to be differentiated from mimics, such as cramps, which are often associated to diseases of the peripheral nervous system and muscles, whereas myalgia is more often a clue to a muscle disease per se..$^{55}$ This symptom has a relatively broad differential diagnosis, ranging from metabolic myopathies to a side effect of the use of statins. ${ }^{56}$

Brazil, among a few other countries, has recently witnessed epidemics of arbovirus infections, including Zika, chikungunya and dengue viral diseases, which present with ample spectra of neurological complications, including meningoencephalitis, myelitis, radiculitis, GBS, and myositis. Myalgia, in or out of the context of myositis, is one of the most common symptoms of this group of arbovirus, besides infections by influenza viruses. ${ }^{57,58,59}$

During the ongoing pandemics of SARS-CoV-2 infection, descriptions of muscle involvement have been consistently reported. ${ }^{7,8,60,61,62,63,64}$ The aforementioned study by Mao et al., ${ }^{7}$ a retrospective observational study of 214 hospitalized patients in the city of Wuhan, China, recognized muscle involvement in $19.3 \%$ of patients. When compared to the patients without muscle symptoms, patients with myalgia had higher serum titers of creatine kinase (CK), regardless of symptoms severity. Myalgias correlated with higher neutrophil and lower lymphocyte counts, higher C-reactive protein and D-dimer levels, indicating increased inflammatory response and blood coagulation function. In addition, these patients had multiorgan damage, including more severe liver 
and kidney laboratory abnormalities. Unfortunately, this publication did not explore other paraclinical markers used to assess the peripheral nervous system, such as nerve conduction studies/electromyography, CSF analysis, and muscle biopsy. ${ }^{7}$ Another study from Wuhan with five patients with pneumonia due to coinfection with SARS-CoV-2 and influenza viruses, demonstrated that $40 \%$ of them had myalgia. ${ }^{60}$

Li et al. ${ }^{61}$ performed a systematic literature review search of the main online databases from December 2019 to February 2020, totaling 1,994 patients with COVID-19 and concluding that $35.8 \%$ of these cases presented myalgia or fatigue. The study did not perform a correlation analysis of these symptoms with any other variable. Huang et al. ${ }^{62}$ collected data prospectively on 41 hospitalized cases of COVID19 , all presenting with pneumonia and abnormal chest CT imaging, and observed myalgia or muscle fatigue in $44 \%$ of them, but reaching $54 \%$ among cases admitted to the ICU. Accordingly, CK and lactate dehydrogenase serum levels were elevated in 33 and $73 \%$, respectively, for all patients, reaching 46 and $92 \%$, respectively, for ICU patients.

Rhabdomyolysis associated with myalgia and fatigue has also been described in cases with severe COVID-19 with potential implications on renal function. ${ }^{63}$ Finally, Han et al. ${ }^{64}$ compared the findings of 25 adults and seven children with confirmed COVID-19, observing that myalgia was disproportionally more common among adults, reaching $52 \%$, although the children had elevated CK levels more frequently than adults (57.1 vs. $4 \%$ ).

\section{Other neurological manifestations}

In addition to the conditions mentioned above, other neurological symptoms, signs and potential complications have been described in SARS-CoV-2 infection. Headache, a non-specific and frequent symptom in common upper airway infections and, in fact, in infections in general, has been described almost invariably in a series of patients with SARS-CoV-2. ${ }^{65}$ In this scenario, however, considering that meningeal involvement and CVD are part of the clinical spectrum of the presentation of SARS-CoV-2 infection, it is essential to rule out meningo-encephalitis and cerebral venous thrombosis in infected patients with refractory or persistent headache. Finally, although unusual, Mao et al. ${ }^{7}$ have reported epilepsy, dizziness, and ataxia in patients with SARS-CoV-2 infection.

\section{CONCLUSIONS}

In conclusion, we aimed at pointing out the main neurological manifestations described in SARS-CoV-2 infection, as of the writing of this review. Their frequency is relevant, occuring in more than one third of the hospitalized patients and varying from mild (i.e., hyposmia and myalgia) to life-threatening complications, such as encephalopathy and stroke. The existing data on the pathophysiological mechanisms contributing to some of these neurological manifestations in the context of SARS-CoV-2 infection reinforce the idea that this virus may be neuroinvasive and/or affects directly or indirectly the CNS or the PNS. ${ }^{66}$ As the pandemic unfolds, pathological studies will be needed to isolate SARS-CoV-2 from neuronal cells, CSF and endothelium of cerebral vessels. Recognition of neurological manifestations of SARS-CoV-2 should be emphasized despite the obvious challenges faced by clinicians caring for critical patients who are often sedated and presenting other concurrent systemic complications.

Finally, the intuitive concern regarding the potential interference of disease modifying agents used for the treatment of immunomediated neurological disorders, such as multiple sclerosis and neuromuscular disorders, has been addressed in a few recent publications that should be of interest to clinicians involved in the care for these patients within the ongoing COVID-19 pandemic. .7,68 $^{-19}$

\section{References}

1. Li F. Structure, function, and evolution of coronavirus spike proteins. Ann Rev Virol. 2016 Sep;3(1):237-61. https://doi.org/10.1146/ annurev-virology-110615-042301

2. Bohmwald K, Gálvez NMS, Ríos M, Kalergis AM. Neurologic alterations due to respiratory virus infections. Front Cell Neurosci. 2018 Oct;12:386. https://doi.org/10.3389/fncel.2018.00386

3. Guan WJ, Ni ZY, Hu Y, Liang WH, Ou CQ, He JX, et al. Clinical characteristics of coronavirus disease 2019 in China. N Engl J Med. 2020 Apr;382:1708-20. https://doi.org/10.1056/NEJMoa2002032

4. Tian S, Hu N, Lou J, Chen K, Kang X, Xiang Z, et al. Characteristics of COVID-19 infection in Beijing. J Infect. 2020 Apr;80(4):401-06. https:// doi.org/10.1016/j.jinf.2020.02.018

5. Ling L, So C, Shum HP, Chan PKS, Chan PKS, Lai CKC, Kandamby DH, et al. Critically ill patients with COVID-19 in Hong Kong: a multicentre retrospective observational cohort study. Crit Care Resusc. $2020 \mathrm{Apr}$ 6. [Epub ahead of print]. PubMed PMID: 32248675.
6. Kochi AN, Tagliari AP, Forleo GB, Fassini GM, Tondo C. Cardiac and arrhythmic complications in COVID-19 patients. J Cardiovasc Electrophysiol. 2020 May;31(5):1003-8. https://doi.org/10.1111/jce.14479

7. Mao L, Jin H, Wang M, Hu Y, Chen S, He Q, et al. Neurologic manifestations of hospitalized patients with coronavirus disease 2019 in Wuhan, China. JAMA Neurol. 2020 Apr. https://doi. org/10.1001/jamaneurol.2020.1127

8. Pleasure SJ, Green AJ, Josephson SA. The spectrum of neurologic disease in the severe acute respiratory syndrome coronavirus 2 pandemic infection: neurologists move to the frontlines. JAMA Neurol. 2020 Apr. [Epub ahead of print]. https://doi.org/10.1001/ jamaneurol.2020.1065

9. Papa SM, Brundin P, Fung VSC, Kang UJ, Burn DJ, Colosimo C, et al. Impact of the COVID-19 pandemic on Parkinson's disease and movement disorders. Mov Disord. 2020 Apr. [Epub ahead of print]. https://doi.org/10.1002/mds.28067 
10. Zhang Y, Xiao M, Zhang S, Xia P, Cao W, Jiang W, et al. Coagulopathy and antiphospholipid antibodies in patients with Covid-19. N Engl J Med. 2020 Apr;382(17):e38. https://doi.org/10.1056/ NEJMc2007575

11. Zhao H, Shen D, Zhou H, Liu J, Chen S. Guillain-Barré syndrome associated with SARS-CoV-2 infection: causality or coincidence? Lancet Neurol. 2020 May;19(5):383-4. https://doi.org/10.1016/ S1474-4422(20)30109-5

12. Helmich RC, Bloem BR. The impact of the COVID-19 pandemic on Parkinson's disease: hidden sorrows and emerging opportunities. J Parkinsons Dis. 2020;10(2):351-4. https://doi.org/10.3233/JPD202038

13. Anioplasty.org. Cardiac arrest deaths at home in new york city have increased by a startling $800 \%$ are some heart attack sufferers dying at home, afraid to call an ambulance for fear of contracting COVID-19 in the hospital? Available form: http://www.ptca.org/ news/2020/0408_INCREASED_DEATHS_NYC.html

14. Moher D, Liberati A, Tetzlaff J, Altman DG, the PRISMA Group. Preferred reporting items for systematic reviews and metaanalyses: the PRISMA statement. PLoS Med. 2009 Jul;6(7):e1000097. https://doi.org/10.1371/journal.pmed.1000097

15. Jin H, Hong C, Chen S, Zhou Y, Wang Y, Mao L, et al. Consensus for prevention and management of coronavirus disease 2019 (COVID-19) for neurologists. Stroke Vasc Neurol. 2020;svn-2020-000382. http:// dx.doi.org/10.1136/svn-2020-000382

16. Beyrouti R, Adams ME, Benjamin L, Cohen H, Farmer SF, Goh YY, et al. Characteristics of ischaemic stroke associated with COVID-19. J Neurol Neurosurg Psychiatry. 2020 Apr;pii:jnnp-2020-323586. https://doi.org/10.1136/jnnp-2020-323586

17. Oxley TJ, Mocco J, Majidi S, Kellner CP, Shoirah H, Singh IP, et al. Large-vessel stroke as a presenting feature of Covid-19 in the young. N Engl J Med. 2020 Apr. [Epub ahead of print]. https://doi. org/10.1056/NEJMc2009787

18. González-Pinto T, Luna-Rodríguez A, Moreno-Estébanez A, AgirreBeitia G, Rodríguez-Antigüedad A, Ruiz-Lopez M. Emergency room neurology in times of COVID-19: malignant ischemic stroke and SARS-COV2 infection. Eur J Neurol. 2020 Apr. [Epub ahead of print]. https://doi.org/10.1111/ene.14286

19. Madjid M, Safavi-Naeini P, Solomon SD, Vardeny O. Potential effects of coronaviruses on the cardiovascular system: a review. JAMA Cardiol. 2020 Mar. [Epub ahead of print]. https://doi.org/10.1001/ jamacardio.2020.1286

20. Asadi-Pooya AA, Simani L. Central nervous system manifestations of COVID-19: A systematic review.J Neurol Sci. $2020 \mathrm{Apr}$ 11;413:116832. https://doi.org/10.1016/j.jns.2020.116832

21. Aggarwal G, Lippi G, Michael Henry B. Cerebrovascular disease is associated with an increased disease severity in patients with Coronavirus Disease 2019 (COVID-19): A pooled analysis of published literature. Int J Stroke. 2020 Apr 20:1747493020921664. https://doi. org/10.1177/1747493020921664

22. Khosravani H, Rajendram P, Notario L, Chapman MG, Menon BK. Protected code stroke: hyperacute stroke management during the Coronavirus disease 2019 (COVID-19) pandemic. Stroke. 2020 Apr:STROKEAHA120029838. https://doi.org/10.1161/ STROKEAHA.120.029838

23. Chen T, Wu D, Chen H, Yan W, Yang D, Chen G, et al. Clinical characteristics of 113 deceased patients with coronavirus disease 2019: retrospective study. BMJ. 2020;368:m1091. https://doi. org/10.1136/bmj.m1091

24. Chen N, Zhou M, Dong X, et al. Epidemiological and clinical characteristics of 99 cases of 2019 novel coronavirus pneumonia in Wuhan, China: a descriptive study. Lancet. 2020 Feb;395(10223):50713. https://doi.org/10.1016/S0140-6736(20)30211-7

25. Lu L, Xiong W, Liu D, Liu J, Yang D, Li N, et al. New-onset acute symptomatic seizure and risk factors in coronavirus Disease 2019: a retrospective multicenter study. Epilepsia. 2020 Apr. [Epub ahead of print]. https://doi.org/10.1111/epi.16524

26. Helms J, Kremer S, Merdji H, Clere-JehL R, Schenck M, Kummerlen C, et al. Neurologic features in severe SARS-CoV-2 infection. N Engl J Med. 2020 Apr. [Epub ahead of print]. https://doi.org/10.1056/ NEJMc2008597

27. Poyiadji N, Shahin G, Noujaim D, Stone M, Patel S, Griffith B. COVID19-associated acute hemorrhagic necrotizing encephalopathy: CT and MRI features. Radiology. 2020 Mar;201187. [Epub ahead of print]. https://doi.org/10.1148/radiol.2020201187

28. Mizuguchi M, Yamanouchi H, Ichiyama T, Shiomi M. Acute encephalopathy associated with influenza and other viral infections. Acta Neurol Scand. 2007 Apr;115(4 Suppl):45-56. https://doi. org/10.1111/j.1600-0404.2007.00809.x

29. Zanin L, Saraceno G, Panciani PP, et al. SARS-CoV-2 can induce brain and spine demyelinating lesions. Acta Neurochir (Wien). 2020 May 4. https://doi.org/10.1007/s00701-020-04374-x

30. Zhang T, Rodricks MB, Hirsh E. COVID-19-associated acute disseminated encephalomyelitis: a case report. medRxiv 2020;04.16.20068148. https://doi.org/10.1101/2020.04.16.20068148

31. Moriguchi T, Harii N, Goto J, et al. A first case of meningitis/ encephalitis associated with SARS-coronavirus-2. Int J Infect Dis. 2020 May;94:55-8. [Epub ahead of print]. https://doi.org/10.1016/j. ijid.2020.03.062

32. Ye M, Ren Y, LvT. Encephalitis as a clinical manifestation of COVID-19. Brain Behav Immun. 2020 Apr;pii:S0889-1591(20)30465-7. [Epub ahead of print]. https://doi.org/10.1016/j.bbi.2020.04.017

33. Duong L, Xu P, Liu A. Meningoencephalitis without respiratory failure in a young female patient with COVID-19 infection in Downtown Los Angeles, early April 2020. Brain Behav Immun. 2020 Apr. [Epub ahead of print]. https://doi.org/10.1016/j.bbi.2020.04.024

34. Wong PF, Craik S, Newman P, Makan A, Srinivasan K, Crawford E, Dev D, Moudgil H, Ahmad N. Lessons of the month 1: A case of rhombencephalitis as a rare complication of acute COVID-19 infection. Clin Med (Lond). 2020 May 5. pii: clinmed.2020-0182. https://doi.org/10.7861/clinmed.2020-0182.

35. Yin R, Feng W, Wang T, Chen G, Wu T, Chen D, et al. Concomitant neurological symptoms observed in a patient diagnosed with coronavirus disease 2019. J Med Virol. 2020 Apr. https://doi. org/10.1002/jmv.25888

36. Xu J, Zhong S, Liu J, Li L, Li Y, Wu X, et al. Detection of severe acute respiratory syndrome coronavirus in the brain: potential role of the chemokine mig in pathogenesis. Clin Infect Dis. 2005 Oct;41(8):108996. https://doi.org/10.1086/444461

37. Li YC, Bai WZ, Hashikawa T. The neuroinvasive potential of SARSCoV2 may play a role in the respiratory failure of COVID-19 patients. J Med Virol. 2020 Feb. [Epub ahead of print]. https://doi.org/10.1002/ jmv. 25728

38. Wu Y, Xu X, Chen Z, Duan J, Hashimoto K, Yang L, et al. Nervous system involvement after infection with COVID-19 and other coronaviruses. Brain Behav Immun. 2020 Mar;pii:S0889-1591(20)30357-3. [Epub ahead of print]. https://doi. org/10.1016/j.bbi.2020.03.031

39. Wang L. Guillain-Barre Syndrome following viral infections: considerations for future treatment and research. Explor Res Hypothesis Med. 2018;3(1):4-5. https://doi.org/10.14218/ ERHM.2017.00035

40. Sedaghat Z, Karimi N. Guillain Barre syndrome associated with COVID-19 infection: A case report. J Clin Neurosci. 2020 Apr;pii:S0967-5868(20)30882-1. https://doi.org/10.1016/j. jocn.2020.04.062

41. Virani A, Rabold E, Hanson T, Haag A, Elrufay R, Cheema T, et al. Guillain-Barré Syndrome associated with SARS-CoV-2 infection. IDCases. 2020 Apr;e00771. https://doi.org/10.1016/j.idcr.2020. e00771 
42. Toscano G, Palmerini F, Ravaglia S, Ruiz L, Invernizzi P, Cuzzoni MG, et al. Guillain-Barré Syndrome Associated with SARS-CoV-2. N Engl J Med. 2020 Apr. https://doi.org/10.1056/NEJMc2009191

43. Alberti P, Beretta S, Piatti M, Karantzoulis A, Piatti ML, Santoro P, et al. Guillain-Barré syndrome related to COVID-19 infection. Neurol Neuroimmunol Neuroinflamm. 2020 Apr;7(4):pii:e741. https://doi. org/10.1212/NXI.0000000000000741

44. Gutiérrez-Ortiz C, Méndez A, Rodrigo-Rey S, San Pedro-Murillo E, Bermejo-Guerrero L, Gordo-Mañas R, et al. Miller Fisher Syndrome and polyneuritis cranialis in COVID-19. Neurology. 2020 Apr;pii:10.1212/WNL.0000000000009619. https://doi.org/10.1212/ WNL.0000000000009619

45. DeVere R. Disorders of taste and smell. Continuum (Minneap Minn). 2017 Apr;23(2, Selected Topics in Outpatient Neurology):421-46. https://doi.org/10.1212/CON.0000000000000463

46. Welge-Lüssen A, Wolfensberger M. Olfactory disorders following upper respiratory tract infections. Adv Otorhinolaryngol. 2006;63:125-32. https://doi.org/10.1159/000093758

47. Giacomelli A, Pezzati L, Conti F, Bernacchia D, Siano M, Oreni L, et al. Self-reported olfactory and taste disorders in SARS-CoV-2 patients: a cross-sectional study. Clin Infect Dis. 2020 Mar;pii:ciaa330. [Epub ahead of print]. https://doi.org/10.1093/cid/ciaa330

48. Lechien JR, Chiesa-Estomba CM, De Siati DR, Horoi M, Le Bon SD, Rodriguez A, et al. Olfactory and gustatory dysfunctions as a clinical presentation of mild-to-moderate forms of the coronavirus disease (COVID-19): a multicenter European study. Eur Arch Otorhinolaryngol. 2020 Apr. [Epub ahead of print]. https://doi.org/10.1007/s00405-02005965-1

49. Beltrán-Corbellini Á, Chico-García JL, Martínez-Poles J, RodríguezJorge F, Natera-Villalba E, Gómez-Corral J, et al. Acute-onset smell and taste disorders in the context of Covid-19: a pilot multicenter PCR-based case-control Eur J Neurol. 2020 Apr. [Epub ahead of print]. https://doi.org/10.1111/ene.14273

50. Gane SB, Kelly C, Hopkins C. Isolated sudden onset anosmia in COVID-19 infection. A novel syndrome? Rhinology. 2020 Apr. [Epub ahead of print]. https://doi.org/10.4193/Rhin20.114

51. Netland J, Meyerholz DK, Moore S, Cassell M, Perlman S. Severe acute respiratory syndrome coronavirus infection causes neuronal death in the absence of encephalitis in mice transgenic for human ACE2. J Virol. 2008;82(15):7264-75. https://doi.org/10.1128/ JVI.00737-08

52. Xu H, Zhong L, Deng J, Peng J, Dan H, Zeng X, et al. High expression of ACE2 receptor of 2019-nCoV on the epithelial cells of oral mucosa. Int J Oral Sci. 2020 Feb;12(1):8. https://doi.org/10.1038/s41368-0200074-x

53. Nataf S. An alteration of the dopamine synthetic pathway is possibly involved in the pathophysiology of COVID-19. J Med Virol. 2020 Apr. [Epub ahead of print]. https://doi.org/10.1002/jmv.25826

54. Roy EP 3rd, Gutmann L. Myalgia. Neurol Clin. 1988 Aug;6(3):621-36.

55. Jain P, Sehgal V. Prominent myalgia - an important clue in the diagnosis of a muscle disorder. World J Pediatr. 2017;13(3):282. https://doi.org/10.1007/s12519-017-0029-2

56. Selva-O'Callaghan A, Alvarado-Cardenas M, Pinal-Fernández I, Trallero-Araguás E, Milisenda JC, Martínez MÁ, et al. Statin-induced myalgia and myositis: na update on pathogenesis and clinical recommendations. Expert Rev Clin Immunol. 2018 Mar;14(3):215-24. https://doi.org/10.1080/1744666X.2018.1440206

57. Mehta R, Soares CN, Medialdea-Carrera R, da Silva MTT, RosalaHallas A, Jardim MR, et al. The spectrum of neurological disease associated with Zika and chigungunya viruses in adults in Rio de Janeiro, Brazil: A case series. Plos Negl Trop Dis. 2018 Feb;12(2):e0006212. https://doi.org/10.1371/journal.pntd.0006212

58. Paliwal VK, Garg RK, Juyal R, Husain N, Verma R, Sharma PK, et al. Acute dengue vírus myositis: a report of seven patients of varying clinical severity including two cases with severe fulminante myositis. J Neurol Sci. 2011 Jan;300(1-2):14-8. https://doi.org/10.1016/j. jns.2010.10.022

59. Davis LE, Kornfeld M, Daniels RS, Skehel JJ. Experimental influenza causes a non-permissive viral infection of brain, liver and muscle. J Neurovirol. 2000 Dec;6(6):529-36. https://doi. org/10.3109/13550280009091953

60. Ding Q, Lu P, Fan Y, Xia Y, Liu M. The clinical characteristics of pneumonia patients coinfected with novel coronavirus and influenza vírus in Wuhan, China.J Med Virol. 2020 Mar. [Epub ahead of print]. https://doi.org/10.1002/jmv.25781

61. Li LQ, Huang T, Wang YQ, Wang ZP, Liang Y, Huang TB, et al. COVID-19 patients clinical characteristics, discharge rate, and fatality rate of meta-analysis. J Med Virol. 2020 Mar. [Epub ahead of print]. https:// doi.org/10.1002/jmv.25757

62. Huang C, Wang Y, Li X, Ren L, Zhao J, Hu Y, et al. Clinical features of patients infected with 2019 novel coronavirus in Wuhan, China. Lancet. 2020 Feb;395(10223):497-506. https://doi.org/10.1016/ S0140-6736(20)30183-5

63. Jin M, Tong Q. Rhabdomyolysis as potential late complication associated with COVID-19. Emerg Infect Dis. 2020 Mar;26(7). https:// doi.org/10.3201/eid2607.200445

64. Han YN, Feng ZW, Sun LN, RenXX, Wang H, Xue YM, et al. A comparative-descriptive analysis of clinical characteristics in 2019-coronoavirus-infected children and adults. J Med Virol. 2020 Apr. [Epub ahead of print]. https://doi.org/10.1002/jmv.25835

65. Qin C, Zhou L, Hu Z, Zhang S, Yang S, Tao Y, et al. Dysregulation of immune response in patients with COVID-19 in Wuhan, China. Clin Infect Dis. 2020 Mar;pii:ciaa248. [Epub ahead of print]. https://doi. org/10.1093/cid/ciaa248

66. Baig AM, Khaleeq A, Ali U, Syeda H. Evidence of the COVID-19 virus targeting the CNS: tissue distribution, host-virus interaction, and proposed neurotropic mechanisms. ACS Chem Neurosci. 2020 Mar;11:995-8. https://doi.org/10.1021/acschemneuro.0c00122

67. Brownlee W, Bourdette D, Broadley S, Killestein J, Ciccarelli O. Treating multiple sclerosis and neuromyelitis optica spectrum disorder during the COVID-19 pandemic. Neurology. 2020 Apr;pii:10.1212/WNL.0000000000009507. https://doi.org/10.1212/ WNL.0000000000009507

68. International MG/COVID-19 Working Group, Jacob S, Muppidi S, Guidon A, Guptill J, Hehir M, et al. Guidance for the management of myasthenia gravis (MG) and Lambert-Eaton myasthenic syndrome (LEMS) during the COVID-19 pandemic. J Neurol Sci. 2020 May;412:116803. https://doi.org/10.1016/j.jns.2020.116803 